\title{
Examining and Organizing the Spatial Development Pattern of Shiraz City using Shannon Entropy and Heldren Models
}

\author{
Morteza Yavari, Fazlollah Karimi Ghotbabadi, Mohammad Rezaei afkham
}

\begin{abstract}
Today, physical growth and spatial development without urban plans are inevitable due to population growth and increasing migration, which in some cities has caused the city sprawl and disrupt the city and degrade its environment. Therefore, it recognizes the spatial and physical development of the city as well as presents a pattern It is considered as one of the most important issues facing urban planners for the future of metropolitan cities, in order to guide it towards sustainable urban development. A model that identifies the directions of physical extension of the city, land use, physical form, and spatial distribution of activities in order to minimize damage to agricultural and environmental land around the city. Shiraz city has experienced five different structure along its life.the existence of different structures in Shiraz caused the observation of multiple patterns of development in it. Accordingly, the purpose of this research is to identify, analyze and organize the spatial development pattern of the city of Shiraz. The research methodology is applied based on its nature, descriptive-analytical, and in terms of its purpose. The data and information needed to conduct the research was collected through library studies and field operations, and then the obtained data were analyzed based on Shannon and Heldren entropy models. Surveying the results of this work shows that in the period of 1385-95, 59\% of its growth has been due to population growth and the remaining $41 \%$, due to horizontal and sprawl growth, which has resulted in decrease in grass population concentration and increase in gross capitation of town land. So, in order to prevent inefficient use of urban lands and reduce the costs of creating infrastructure and facilities and urban amenities and achieving sustainable urban development, the proposed model for physical development of the city of Shiraz is a compact city model, which, given the existing capacities and potentials, It can be used in the city.
\end{abstract}

Keywords : physical development, urban growth pattern, Shannon entropy, Heldren model, Shiraz.

\section{INTRODUCTION}

From the beginning of the 19th century, urban issues began to take on a new form because the growth of industry and technology increased the size of cities, and so the physical growth and development of cities was influenced not only by

Revised Manuscript Received on September 25, 2019

* Correspondence Author

Morteza Yavari, Academic Member of Zabol University, - Department of Urban Planning, Faculty of Art and Architecture, University of Zabol, Zabol, Iran.

Fazlollah Karimi Ghotbabadi, Ph.D. student of Geography and Urban Planning, University of Isfahan, Isfahan, Iran

Mohammad Rezaei afkham, Academic Member of Zabol University, Department of Architecture, Faculty of Art and Architecture, University of Zabol, Zabol, Iran natural factors but also by human factors (ghadami and yousefian 2014,63). An examination of the physical developmental stages of cities around the world reveals that technological changes of the last century, especially transport technology, have resulted in the rapid physical growth of cities and the transformation of cities. The disproportionate growth and development pattern, which is considered as the Sprawl pattern in world literature, is considered to be a Planned-model in developed countries, and in undeveloped countries is a no-plan model, Due to the extension and extension of cities, the extension of urbanization and environmental problems in developing countries (Majedi 1999, 6)

The cities of Iran, which had grown and evolved through historical periods based on national creativity and ingenuity, gradually changed over the course of several decades, losing the physical properties of cultural values of their artistic and historical social features. (Habibi et al.2011,16)

In Iran, as long as urban growth patterns are organic and endogenous and local determinants of urban growth, urban land has provided enough urban traditional uses and has organized the urban space according to the economic, social and security conditions of the city. But since urban development became an exogenous nature and oil revenues were injected into the urban economy and our cities were incorporated into the world economy, investment in urban land intensified, and this weakness of the private market without land application It has dictated the pattern of development in many Iranian cities(Majedi 1999, 6). This has caused disruption to the urban land market, and in particular the extensive use of land within the city limits and the horizontal extension of cities (Athari 2000, 36).

In order to increase the growth of urbanization in Iran, the process of concentration and establishment of urban population in the provincial capitals has been faster. Shiraz is one of the most important cities in Fars province and southern Iran with different economic, cultural, service and economic attractions. A survey of the population growth of Shiraz during the last three censuses shows that it has had the highest growth rate during the years 1986-2006. The reason for this increase in population growth, in addition to government policies and lack of population control at the national level, must be attributed to events such as the Iran-Iraq war and the influx of war refugees and severe urban immigrants during their growth. (shahr \& khane Consulting Engineers2007, 16). 
One of the major problems in urban planning with regard to population growth and physical development in Shiraz is the lack of suitable locations and the prevention of infrastructure and agricultural land, determining the appropriate direction and how to physically expand the city to meet current needs and demands that should be studied and reviewed. In other words, the most important issue facing urban development here is their future development. In other words, the most important issue facing urban development here is their future development.

Today, with the pervasive consequences of horizontal urban extension in various aspects of socio-environmental, economic and economic control of physical extension, over-planning is unimportant and must be carefully and adequately addressed by urban planners and decision makers.

The Shiraz Master Plan is projected to accommodate about 200,000 of the $16,500,000$ people in the south and southeast in the horizon of the plan (2019) and about 100,000 people reside in breakaway settlements and lands such as Bazin and Mianrood, and about 135,000 others reside in vacant lands in the city and suburbs. But the development trend reflects an influx of people and housing cooperatives toward west and northwest. This factor, along with changes in land prices and economic behavior of the people, has led to the linear development of Shiraz. The disagreement between decision-makers and policy-makers with employee housing co-operatives and construction companies as well as popular tendencies has led to the implementation of the master plan, strategies and forecasts of the project despite several years of master plan horizons, and the continued construction of unproductive structures, especially in the northwest.

In 2013, by approving the annexation of areas the Qasr Qomshah, Guyim and Dukohak areas along the northwest axis of Shiraz, the trend of linear development of the city has accelerated, which has caused many problems for various people of this city. Therefore, it is necessary to adopt an appropriate plan for physical development with the aim of presenting existing problems. Numerous researches have been carried out in the field of physical development of cities, the following are some of them and the results of these studies:

Ebrahimzadeh and Habibi (2010), in an article entitled An Analysis of the Physical Extension and Growth Factors of Tabas City after the Earthquake Using the Heldren Entropy Model, concluded in part of their paper that 55\% of Tabas City's physical growth in Population growth in the years 1971-85 was 45\%, with horizontal and sprawl city growth. However, according to the authors' calculations for the next 19 years, the current city limits will be met by the intra-contextual extension of population needs.

Pourmohammadi, Jamali and Asgari Zamani (2008) in a paper entitled Zanjan Spatial-Physical Extension Assessment on Land Use Change in Zanjan City during 1974-2004 have concluded that correlation, intensity, extent and mechanism of land use conversion and change in Zanjan, As a consequence and embodiment of its spatial-physical extension it shows. Accordingly, it was found that, in terms of intensity and scale of urban land use, respectively, Dry farming, brownland, garden and irrigated land affected their spatial-physical development.
Mohammadzadeh (2007) in an article entitled Environmental Impact Assessment of Accelerated Physical Development of Cities (with Emphasis on Tehran and Tabriz Cities) has concluded that by approaching environmental goals with planning and design, in addition to protecting agricultural lands, we can minimize environmental vulnerability.

\section{THEORETICAL FRAMEWORK}

Among the recent ideas and terms of urban planning in the urban context, such as urban condensation, sustainable city, compact city, new urbanism, smart growth, urban sprawl that have been incorporated in the literature of urban research for the last half century, today is the focus of most urban conferences and seminars in developed countries.

The history of term goes back to the mid-20th century, when the use of personal cars and the development of the highway system intensified the development of urban spaces in the United States, enabling citizens to move out of the city and into Unbound construction to reside on the outskirts of cities (Hess 2004, 4).

In general, in the systemic approach, the development of cities can be divided into two processes, spontaneous and self-organizing (Wu 2000, 1). In the process of self-organization, development occurs in any location based on the development of the past time that occurred in the nearest neighbor of that place; So the neighborhood has an important impact on the process. The pattern of self-organization growth is often agglomerated or densely influenced by socio-economic self-organization activities (Cheng 2003, 2). This agglomeration can occur in different clusters around cities. Of course, any kind of development focus does not represent the process of organizing itself, but the existence of a specific factor in a given region can be a factor in the development focus alone. As a result, there is another process called spontaneous growth. This process is influenced by factors beyond the neighborhood. Due to the nature of such factors the concentration of development is less in areas that are most affected by spontaneous growth; in other words, this concentration is often less in the short run. This scattered urban development has profound effects on the sustainability of human settlements and people's well-being. The spontaneous process represents the development independent of successive land use changes in the region (Audriac \& etal, 1990: 5).

The two self-organizing and spontaneous development processes have been implemented differently in simulated physical development models of cities.Clark et al. 1997, to simulate urban land development, presented a project called SLEUTH, which operates on an automated cell model, and has so far been implemented in various areas such as the coasts of Francisco, Washington - Baltimore, Mexico, and the cities of Lisbon Portugal and Boro in Brazil is executed. In this model, the process of urban development is divided into four stages, the first stage being spontaneous growth and the next two stages under the heading of diffuse growth and organizational growth, in effect expressing the process of self-organization.

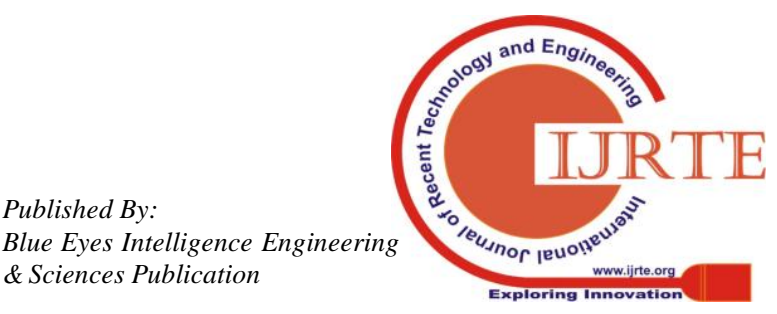


In 2002, Elmida et al. Presented a DINAMIC model to simulate different land use changes in the city of Buro in Sao Paulo, Brazil, using two extension and fragmentation processes.

The first process occurs at the boundary of developed areas and the second process results in the production of small developed lands. (Figure 1) schematically illustrates two development processes at two T1 and T2 times (Mirbagheri, 2009: 53).

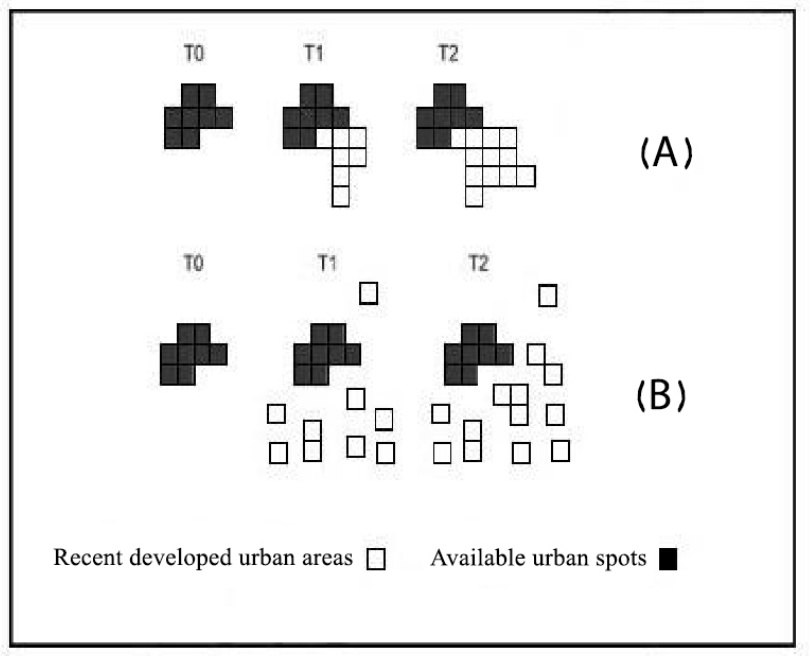

Figure 1. Urban Development Models (Mirbagheri et al 2009, 53)

\section{METHOD}

The research method in the present study is based on nature is descriptive-analytical and on the basis of purpose is applied-developmental. Although other methods such as causal, correlation, etc. have been used, the main research approach is based on descriptive-analytical method. The data and information needed for the research were collected through library studies and field operations and then the data were analyzed using Shannon and Heldern entropy models.

\section{Shannon entropy model}

This model is used to analyze and determine the urban clutter phenomenon. The general structure of the model is as follows (Hekmatnia and Mousavi 2006,189):

$$
\mathrm{H}=\sum_{\mathrm{i}=1}^{\mathrm{n}} \text { pi. } \mathrm{L}_{\mathrm{n}} \text { pi }
$$

In this equation $\mathrm{H}$ : Shannon entropy value, pi: ratio of constructed area (total residential density) to I area to total area made is the sum of zones and $n$ the sum of zones. The value of the Shannon entropy value is from zero to $\operatorname{Ln}(\mathrm{n})$, where the value zero represents very dense physical development, Whereas Ln (n) indicates sporadic urban physical development. In fact, when the entropy value is greater than Ln (n), sprawl growth occurs.

\section{Heldern Model}

One of the basic methods to determine urban sprawl growth is the use of the Heldren method. Using this method we can determine how much of the city's growth is due to population growth and how much of it is due to urban sprawl. The equation steps of this model are as follows (Beck \& etal 2003 , 101):

$$
A=\frac{A}{p}
$$

In relation (1) the gross per capita (a) is equal to the sum of the area of land (A) divided by the population (p). According to equation (1), it can be said that the total land occupied by an urban area (A) is equal to the gross productivity per capita (a) and the population number (p). In which case we will have:

$$
A=p \times a
$$

According to Heldren's method, if, over a period of time $(\Delta t)$, the population increases with equal growth $(\Delta p)$ and land use changes $(p)$, the total urban land $(\Delta)$ increases with the substitution in relation (2):

$$
A+\Delta A=(P+\Delta P) \times(a \times \Delta a)
$$

By replacing relations (2) and (3) and dividing it by (A), we can obtain changes in the area $(\triangle A / A)$ of the converted city area over time $(\Delta t)$ :

$$
\frac{\Delta A}{\mathrm{~A}}=\frac{\Delta \mathrm{P}}{\mathrm{P}}+\frac{\Delta \mathrm{a}}{\mathrm{a}}+\left(\frac{\Delta \mathrm{P}}{\mathrm{P}}\right) \times\left(\frac{\Delta \mathrm{a}}{\mathrm{a}}\right)
$$

Thus, following the Heldren model, relation (4) states that the growth rate of a city is equal to the sum of the percentage of population growth and the percentage of gross per capita growth; in other words, relation (4) is:

Gross Per capita Gross Percentage + Population Growth $=$ Percentage of Gross Urban Area Growth

Accordingly, the population growth contribution from the sum of the land (the spiral) is obtained by the ratio of the percentage change of the total population in a given period to the percentage change of the total area of the land over the same period, which can be expressed as follows:

Land Growth Share $=\frac{\text { Percentage of total population growth }}{\text { Percentage of total land area growth }}$

In the case of land per capita, we can calculate the share of city land growth:

$$
\text { Land Growth Share }=\frac{\text { Percentage of total land use growth Per capita }}{\text { Percentage of total land area growth }}
$$

Based on the population growth model, Heldern presents a general growth model to complement his model:

$$
P(T)\left(1+g_{p}\right)^{t}
$$


Where $\mathrm{p}(\mathrm{t})$ is the population at time $\mathrm{t}, \mathrm{p} 0$ is the initial population, gp is the rate of population growth over time, the following relation can be used to solve gp:

$\mathrm{n}\left(1+\mathrm{g}_{\mathrm{p}}\right)=\left(\frac{1}{\mathrm{t}}\right) \mathrm{l}_{\mathrm{n}}\left(\frac{\mathrm{p}(\mathrm{t})}{\mathrm{p}_{\mathrm{o}}}\right)$

Since $\ln (1+\mathrm{x})$ for values less than $\mathrm{x}$ is approximately equal to $x$, Equation (9) can be written as follows:

$$
g_{\mathrm{p}}=\left(\frac{1}{\mathrm{t}}\right) \ln \left(\frac{\mathrm{p}_{(\mathrm{t})}}{\mathrm{p}_{0}}\right)
$$

This form of growth rate inference can also be written for the land area (A) and land use per capita (a):

$$
\begin{gathered}
g_{a}=\left(\frac{1}{t}\right) \ln \left(\frac{a_{(t)}}{a_{0}}\right) \\
g_{A}=\left(\frac{1}{t}\right) \ln \left(\frac{A_{(t)}}{A_{0}}\right)
\end{gathered}
$$

So based on three population growth rate equations, we can write Heldren's paper as follows:

$$
g_{p}=g_{a}=g_{A}
$$

Substituting the formula (relationship 10 through 12) for the growth rate and the ratio of the end-of-period values and the beginning of the period of variables $p$, $\mathrm{a}$ and $\mathrm{A}$ over the time interval studied, we will have :(14)

Table 1. Population Growth Trends in Different Areas of Shiraz (2006-2016)

\begin{tabular}{|c|c|c|c|c|c|c|c|c|}
\hline \multirow{2}{*}{ regions } & \multicolumn{2}{|c|}{2006} & \multicolumn{2}{c|}{2011} & \multicolumn{2}{c|}{2016} & \multicolumn{2}{c|}{ Annual Growth Rate (\%) } \\
\cline { 2 - 10 } & Number & Percentage & Number & Percentage & Number & Percentage & $\begin{array}{c}2006-201 \\
1\end{array}$ & $\begin{array}{c}2011-201 \\
6\end{array}$ \\
\hline 1 & 187628 & 15.2 & 220519 & 15.10 & 159513 & 9.49 & 3.28 & -6.27 \\
\hline 2 & 193866 & 15.7 & 180931 & 12.39 & 178116 & 10.60 & -1.37 & -0.31 \\
\hline 3 & 177668 & 14.5 & 189190 & 12.95 & 197458 & 11.75 & 1.26 & 0.86 \\
\hline 4 & 266032 & 21.6 & 223180 & 15.28 & 254503 & 15.14 & -3.45 & 2.66 \\
\hline 5 & 163042 & 13.3 & 147853 & 10.12 & 156105 & 9.29 & -1.94 & 1.09 \\
\hline 6 & 51969 & 4.2 & 160588 & 10.99 & 119635 & 7.12 & 25.31 & -5.71 \\
\hline 7 & 131952 & 10.7 & 183346 & 12.55 & 186500 & 11.10 & 6.8 & 0.34 \\
\hline 8 & 55194 & 4.5 & 44397 & 3.04 & 35727 & 2.13 & -4.26 & -4.25 \\
\hline 9 & - & - & 110661 & 7.58 & 140718 & 8.37 & - & 3.82 \\
\hline 10 & - & - & - & - & 137297 & 8.17 & - & - \\
\hline 11 & - & - & - & - & 115000 & 6.84 & - & - \\
\hline Total & 1227331 & 100 & 1460665 & 100 & 1680572 & 100 & 3.54 & 2.84 \\
\hline
\end{tabular}

\section{Physical examination of Shiraz}

The Development and Civil Development Plan assess the physical state of Shiraz:

There are five distinct areas in the physical context of the city:

A) Historic City Area: About 350 hectares that comprises the core of the city's formation. Its urban texture is compact and dense and its buildings are historic and largely worn. The car transportation network is poor and inefficient. Building density is high despite low building height, population density is high, and due to health and quality control of

\section{RESULTS AND DISCUSSION}

The developmental study of the city of Shiraz shows that this city has grown on a bed of north-south extension confined to the altitudes north, southwest and lake Maharloo in the east. Dry river as a natural factor shaping the communication axes along the longitudinal plain (northwest - southeast) and construction axis has created the perpendicular direction of the main structure of the city that has developed around the very slow and slow development of the last centuries and the developments of the last few decades, and now the city has gained its most widespread physical and population status in the history of the city in (Table 1).

housing and environmental problems, land prices in this area are low and the housing of the poor and immigrants.

(B) The central context of the city: including post1951 extensions, high construction density, the number of floors especially on the high-traffic sidewalks, and the level of the road network due to the density of urban functions inadequate. Land prices in these areas, especially in high-rise commercial buildings and as old as buildings, can reach up to 40 years. 
C) North and North West extension: It is favored by the affluent, with high construction quality, low population density and high land prices.

D) Southern Margin Extensions: Includes unnecessary extensions outside the scope of the approved master plan. Due to the weakness of the financial resources of the inhabitants, the size of the small plots, the quality of the nozzle building and the population density are high. Due to the lack of a specific design, its physical texture lacks consistency and conforms to order. Its network of passages has been created spontaneously following the rural paths (Abdollahzadeh 2005, 55).

E) Northwest Breakaway Developments: The high cost of land for construction of the Shiraz area and the tendency to reside in the northwest coast of Shiraz have caused the breakaway builders in the northwest due to favorable climatic conditions. The constructions carried out on this axis are not organic in development and have certain characteristics. The low land prices and the attractiveness of the region have made it possible for different economic and social groups to reside there (Naghsh Jahan Pars consulting Engineers 1989, 4).

We have seen many residential settlements around Shiraz since the 1990s. Settlements such as Golestan, Shahid Beheshti, Hafez, and many of which are in the North West. On the other hand, with the incorporation of the villages of Guyim, Dukuhak and Qasr-e Qomsheh into the district of 2013 and the approval of District 10 Municipality, the trend of uneven and linear development of the city has been further exacerbated, which has caused numerous problems in various areas in (Figure 2).

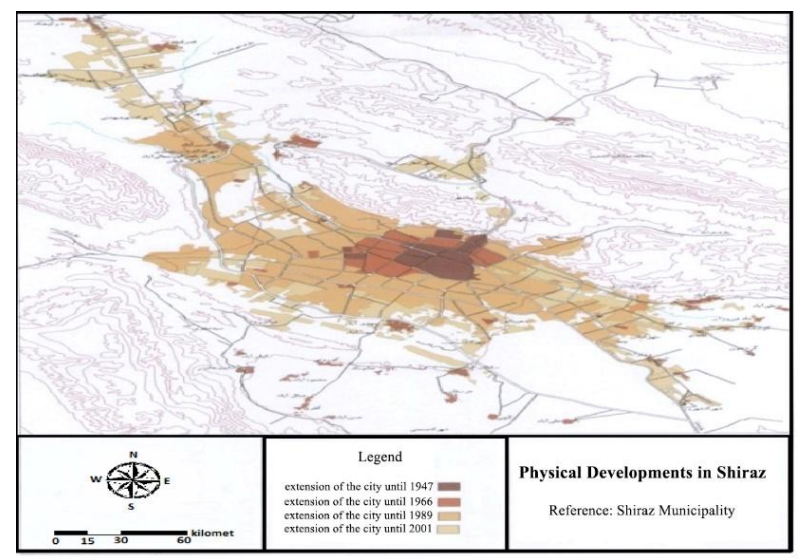

Figure 2. Physical-spatial extension of Shiraz in the past periods

Reference: Shiraz Municipality

Analytical Model of Physical Extension of Shiraz City In order to analyze the shape of the city and to plan for the future physical extension, although various models such as the Shannon entropy model, Heldren, the Moran coefficient and the like are examined for the urban form measurement, However, although Moran and Gray coefficients are potentially spatially determinant of spatial structure, their variation is sometimes complex (Anseline 1995, 2). At the same time, the relative entropy index is better than the others.

Table 2. Calculation of the entropy value of Shiraz regions in 2006

\begin{tabular}{|c|c|c|c|c|}
\hline Region & $\begin{array}{c}\text { Area } \\
(\mathbf{H e})\end{array}$ & $\mathbf{P i}$ & $\mathbf{L n}(\mathbf{p i})$ & $\begin{array}{c}\text { Pi.Inp } \\
\mathbf{i}\end{array}$ \\
\hline $\mathbf{1}$ & 1477.7 & 0.120 & -2.120 & -0.254 \\
\hline $\mathbf{2}$ & 1641 & 0.122 & -2.103 & -0.256 \\
\hline $\mathbf{3}$ & 1011.1 & 0.075 & -2.590 & -0.194 \\
\hline $\mathbf{4}$ & 1130 & 0.084 & -2.476 & -0.207 \\
\hline $\mathbf{5}$ & 1980 & 0.417 & -1.917 & -0.281 \\
\hline $\mathbf{6}$ & 2520 & 0.177 & -1.732 & -0.306 \\
\hline $\mathbf{7}$ & 1331.4 & 0.098 & -2.323 & -0.227 \\
\hline $\mathbf{8}$ & 758 & 0.056 & -2.882 & -0.661 \\
\hline $\mathbf{9}$ & 1612.5 & 0.121 & -2.111 & -0.255 \\
\hline$\sum$ & 13461.7 & 1.00 & - & -2.196 \\
\hline
\end{tabular}

Reference: Author's calculations

$$
G=\frac{\mathrm{H}}{\mathrm{L} \text { nK }}=\frac{2 / 282}{2 / 372}=0 / 962
$$

(Table 2) and (Table 3) show that, given the Shannon entropy model, which has a value of $\mathrm{Ln}$ between zero and one, and considering the sprawl growth of Shiraz, the growth of this city has been sparse. In the case of Shiraz, the Heldren model variables are as follows:

$$
\begin{gathered}
(\operatorname{Ln}) \frac{1680572}{1227331}+(\operatorname{Ln}) \frac{136.7}{109.7}=(\operatorname{Ln}) \frac{22973}{17889} \\
(\operatorname{Ln}) 1.3692+(\operatorname{Ln}) 1.2461=(\operatorname{Ln}) 1.2842 \\
\frac{0.314}{0.534}+\frac{0.220}{0.534}=\frac{0.534}{0.534} \\
0.59+0.41=1
\end{gathered}
$$

Therefore, physical growth in Shiraz from 1385 to 1395 was only $59 \%$ of population growth and $41 \%$ of growth was due to horizontal growth and sprawl, which resulted in a decrease in gross population density and an increase in GDP per capita.

\section{CONCLUSION}

Shiraz is the most important metropolis in the south of Iran. An examination of the physical development of the city during the years 2006-2016 reveals that approximately 4427 acres have been added to the city. The physical and geographical constraints surrounding the city of Shiraz have changed the pattern of development from nuclear to linear, with the distance now reaching more than 45 kilometers east to west. The city's longitudinal and linear extension has caused many problems in different parts of the city, primarily in the service sector. Although spatially administrative, it is currently divided into 11 service areas, and even in development plans, it will reach 12 areas, but it is necessary to adopt appropriate policies for its physical growth. 
Three scenarios are proposed for physical extension of Shiraz:

\section{1- Linear Extension Pattern}

Due to the linear form of the Shiraz plain, the constraints around the plain, and the historical background, the extension of the city has followed this pattern to some extent. The connecting axes of Shiraz-Sepidan Road and Chamran Boulevard are the backbone of this model. Of course, this kind of extension will cause numerous problems such as environmental degradation, service problems and polarization of the city. Of course, apart from the problems mentioned, this model can also have benefits such as reducing traffic congestion and decentralization from the city's core.

\section{2- High density city pattern}

The important point about Shiraz city extension pattern is to avoid population density and high construction density. The tendency for high building density can only be seen in specific areas of the city. The existence of more than 1350 hectares of historical and historical fabric in the city of Shiraz has provided the potential for this type of development pattern. In fact, by creating and expanding this model, urban environment improvement is reasonably and appropriately feasible.

\section{3-Disconnected extension pattern}

In northwest (Shiraz-Sepidan) axis with Shahid Beheshti, Esteghlal, Golestan townships and in east and south-east axis (Shiraz-Fasa) with Shahrshahr city, the lateral city has expanded due to less than $15 \mathrm{~km}$ of textured areas. The main town, the overflow areas are connected to the mother city. There are also geographical limitations; for example, the development of the city to the north due to mountainous conditions is not possible or the development to the east faces the problem of transferring water from the Shiraz plain to Sarvestan plain. There are also problems in the southern parts of the country, such as high groundwater levels, high quality agricultural land. Development of the city to the north-west is also difficult, as factors such as low groundwater levels, people's tendency to live in these areas, and lack of agricultural capability in the area are some of the positive factors, but other factors must be addressed. He pointed to higher service costs, increased Shiraz air pollution and the destruction of Qasr al-Dasht gardens. In any case, one of the most important issues in the field of urban planning is the issue of physical development of a city which has to be looked at in different dimensions and Shiraz is not an exception to the rule, and the necessity of applying appropriate strategies in this regard. Planned physical growth is needed. Among the mentioned patterns and considering the geographical conditions in Shiraz, it seems that the crowded city pattern is the best option for growth of this city. The presence of more than 1,650 hectares of worn-out old tissue in the central part of Shiraz has created the potential in this city to address the anomalies, social problems and problems faced by these types of textures. It is no longer possible to halt the growth of the city without a plan.

\section{REFERENCES}

1. Abdollahzadeh Fard, AS (2004). Investigating the Directions and Factors Affecting the Physical Development of Shiraz during 1921-2003 and Modeling the Development Paths to Horizon 2021 Using Geographic Information System, Master of Urban Planning. Shiraz university. Page 149.

2. Anselin, L. (1995). space stat version 1.80 users; Guide, university of Illinois, urbanachampaign, II

3. Athari, K. (2000). "Towards the Effectiveness of Government Interference in the Urban Land Market". Journal of Housing Economics. 30 (4): 41-34.

4. Audirac, I. shermyen A.H, smith M.T. (1990). Ideal urban from and visions of the good life, Journal of American planning Association, 56(2): 470480

5. Beck, Roy kolankiewiez, Leon \& camarota, steven A,(2003),outsmarting smart grow th,populationgrowth, Immigration, and the problem of sprawl growth,Imigration studies, washington

6. cheng, J. (2003). Modelling spatial and Temporal urban growth, UPLA, Enschede, N1, ITC:203

7. Ebrahim Zadeh Asmin, h. Ebrahimzadeh, A. and Habibi, M. (2010). "An Analysis of the Physical Extension and Spiral Growth Factors of Tabas City after the Earthquake Using the Heldren Entropy Model". Journal of Geography and Development. 19 (4): 46-25.

8. Ebrahimzadeh, AS and Rafiei, Q (2009). "An Analysis of the Physical-Spatial Pattern of Marvdasht City Using Shannon and Heldren Entropy Models and Presenting the Desirable Future Extension Pattern". Journal of Human Geography Research. 69 (2): 138-123.

9. ghadami MH and Yusefiani P. (2014). An Analysis of Spatial Structure Changes in Esfahan City by Avoiding Air Pollution. Urban Planning Studies Quarterly.

10. Habibi K. Behzadfari M. Meshkinini A. Alizadeh AH and Mottaki. (2011). Assessing the Impacts of Urban Development on the Destruction and Quality Improvement of the Space of the Old Iranian City Iranian-Islamic Studies Quarterly.

11. Hekmatya, H, and Mousavi, m. (2006). Model application in geography with emphasis on urban and regional planning. first volume. Modern Science Publications. Page 372.

12. Hess,G.R. (2001). Just what is sprawl Anyway? www4.ncsu.Edu/ grhess

13. Iran Statistical Center, Results of the General Census of Housing Population of Fars Province, 1986-2016.

14. johanson, E.A.J. (1998). the organization of spage in development press,countries. Cambridge, Harvard university.

15. Majedi, h. (1999). "Land is the main issue of urban development". Abadi Journal. 33 (2): 14-3

16. merlin,p. (2000). methods Quantitative and spase urban publisher, university of paris.

17. Mirbagheri, B and Mutkan, AS. (2009). "Quantitative Assessment of Urban Land Development Concentration Using Ripley, s K Function in GIS (Case Study: Islamshahr, Robat Karim and Nasimshahr)". Geographical Research, 69 (2): 66-51.

18. Mohammadzadeh, R. (2007). "Environmental Impact Assessment of Accelerated Physical Development of Cities with Emphasis on Tehran and Tabriz Cities". Journal of Geography and Regional Development. 9 (2): 112-93.

19. Naghsh e Jahan Pars Consulting Engineers. (1989). Justification Report of Shiraz Civil Development Plan.

20. Pour Mohammadi, M. Jamali, F and Asghari Zamani, A. (2008). "Evaluation of Spatial-Physical Spatial Development of Zanjan with Emphasis on Zanjan Urban Land Use Change". Journal of Geographical Research. 63 (1): 46-29.

21. Shahr o khane consulting engineers. (2007). Overview of Shiraz Detailed Plan. first volume.

22. wu,f. (2000).A parameter isedd urban cellular model combining spontaneous and self organising growth, Geocomputation: Innovation in GIS 7. p.A.A.D. Martin london, Taylor \& francis. london 24(2): pp. 73-85. 